\title{
More training modules for an advanced interactive course on optical design
}

Brian Blandford, Heidi Malaka

Brian Blandford, Heidi Malaka, "More training modules for an advanced interactive course on optical design," Proc. SPIE 9666, 11th Education and Training in Optics and Photonics Conference, 96660T (5 June 2009); doi: 10.1117/12.2208048

SPIE Event: Eleventh International Topical Meeting on Education and Training in Optics and Photonics, 2009, St. Asaph, United Kingdom 


\title{
More training modules for an advanced interactive course on optical design
}

\author{
Brian Blandford $^{1}$ and Heidi Malaka ${ }^{2}$ \\ [1]Ancient and Modern Optics, 5 Kingsway Mansions, Red Lion Square, London \\ WC1R 4SE UK \\ [2]University of Applied Sciences, Carl-Zeiss-Promenade 2, 07745 Jena, Germany
}

\begin{abstract}
The purpose of this paper is to explain in more detail some of the ideas first presented at earlier Institute of Physics and S.P.I.E. conferences, and to give an update on the work that has been done by the authors and others to develop online tutorial materials, particularly for those who do not intend to specialise in optical design. The latest additions to these courses, involving real lens design and analysis tasks, are now available on the Ancient and Modern Optics web site in unrestricted download format.
\end{abstract}

\section{KEYWORD LIST}

Lens design, optical design, remote learning, on-line course, OSLO-EDU.

\section{INTRODUCTION}

The question of remote teaching of optics in general and optical design in particular has been of interest to the first author since 2000. At that time he conducted an informal investigation into remote teaching methods in connection with a vacancy for a course manager for the MSc course at an academic institution. This included a brief to bring as much of the material of the course as possible onto the internet to enable at least parts of the course to be undertaken without attendance at the college involved. He was of course aware of the pioneering work of the Open University. What surprised him at the time was how much progress had been made, particularly in countries like Australia and the USA where access to higher education can involve travel over long distances. The internet was relatively young at the time. But some quite sophisticated software packages were already on the market, some of which aimed to integrate the needs of both in-house and remote course participants in academic institutions. Some aspects of remote learning were even compared favourably to conventional methods. For example, the view was expressed that access to a busy teacher was sometimes easier by email than by waiting in the queue outside the teacher's office.

He presented some of the results of this study at Photon02 in an impromptu paper ${ }^{1}$ presented at very short notice. This related some of his experience in teaching optical design, not as an academic discipline within a physics department, but as a number of concentrated stand-alone courses, tailored to meet the needs of a specific audience.

\section{WHY REMOTE LEARNING?}

The second paper ${ }^{2}$ on this subject was presented by the authors in 2005. This proposed, in essence, that optical design should not in future be regarded as a specialised discipline restricted to the small and diminishing number of current full-time professionals with a background in applied physics. It was rather that optical design should be looked on as an additional skill of an engineer who has a full-time occupation in another field such as mechanical design. This skill can be acquired both over the internet and through professional short courses.

If this approach is taken seriously, the candidates for the courses will change. There will be fewer who are students in full-time education, more who are engineers broadening their skills base. Also, because the audience will change, the teaching materials should change (particularly since interactive graphics and Java have now become widespread) and so should the teaching methods.

Optical design is particularly suited to remote teaching methods for the following reasons:

Many topics can be conveyed better in pictures than in words or formulae.

Interactive computer graphics are already an integral part of today's optical design software.

Eleventh International Topical Meeting on Education and Training in Optics and

Photonics, edited by K. Alan Shore, Deb Kane, Proc. of SPIE Vol. 9666, 96660T

(C) 2009 SPIE, OSA, IEEE, ICO · doi: 10.1117/12.2208048 
Since video is unnecessary, connections to the internet for remote learning do not need to be broadband.

$\square$ The teaching material is greatly enhanced by the use of colour which can be provided online at no extra cost.

$\square$ The software necessary for hands-on experience can be downloaded free of charge.

\section{WHO NEEDS IT?}

There is now so little institutional teaching of optical design that, in most parts of the world, remote learning is in fact the only way in which future demand for optical designers can be met. In many countries, including the UK, demand already exceeds supply. This is evidenced by vacancies advertised month after month on the web. For the same reason, new courses can be developed afresh, outside the constraints of academia, using few, if any, traditional material and methods.

Another point is that optical design has come a long way since the designer could afford to spend months perfecting a design. Results are expected much sooner. Also today's designer is expected to have proficiency in designing for a much wider range of applications. The specialised optical knowledge needed to design, say, a pair of binoculars, a medical endoscope, a LIDAR objective and a spectrometer, is essentially the same. However the surrounding issues - whether of mechanical engineering, commercial, environmental, or optical manufacture - differ greatly in each case. So the model we are trying to promote is not, for example, an electronics specialist contacting an optical designer for help with a new product. It is rather of, say, an electronic engineer who spends evenings developing optical design skills to enable him to undertake small optical design tasks during the day without outside help. This frees the specialist designer to dedicate more time to specialised optical desian tasks.

\section{WHAT ARE OTHER PEOPLE DOING?}

The temptation with many internet applications is to allow the technology to drive the content rather than the other way round. For teaching of pure optics, there are many websites offering excellent applets in Java which illustrate individual phenomena. Links to some of these can be found on the amoptics.com website under "Links." Very few, however, teach optical design as such except at the simplest level.

One trend in recent years has been the OpenCourseWare movement ${ }^{3}$, by which universities make large amounts of teaching materials, course notes and video lectures freely available to the worldwide internet community. This reportedly benefits the university by improving the skills of those admitted for full-time study, as well as improving the quality of the teaching material itself. The movement first began at the Massachusetts Institute of Technology in 2003, but has now grown into the OpenCourseWare Consortium (http://www.ocwconsortium.org/) with 200 participating institutions. Currently this has 2386 courses on offer. One good example in the field of optics is the series of 49 video practical demonstrations ${ }^{4}$ by Shaoul Ezekiel of MIT. Others are unfortunately marred by the absence of diagrams originally copied from copyright textbooks, which may not be published on the internet.

\section{WHAT ARE THE BUILDING BLOCKS?}

One of the gratifying aspects of this work is that material which has been originated using familiar Microsoft Office tools can readily be adapted and converted to formats best suited to the internet. The progression from simple textual material to the fully interactive graphical presentation is illustrated by the following examples, all but one of which have now been implemented on the amoptics.com website. The figures give sample images from each.

Text: The glossary of terms used in optical design ${ }^{5}$ in English, French, German, Italian and Spanish is now available for free

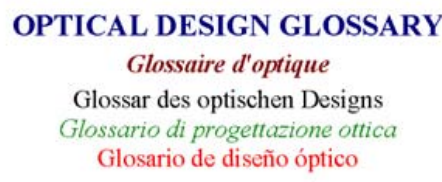

Figure 1 Sample of text from the multilingual glossary download as a PDF. This uses colour to discriminate between the different languages in a way which would be prohibitively expensive if published on paper. The header for this is illustrated in Figure 1. 
Sequential pictorial: The basis that Ancient and Modern Optics use to originate their visual aids is Microsoft PowerPoint. The two presentations ${ }^{6}$ on "Lens Manufacture" and "Optical Assembly" have been converted for internet display in a format which is easy to access but which discourages downloading. One slide, which illustrates the testing of the first polished side of a lens for form error, is given in Figure 2 as an example.

Stepped sequential pictorial: The step-by-step assembly of a diagram, such as would be created by a chalk-and-blackboard teacher, can be simulated in a PowerPoint presentation by rapidly progressing through the slides. An example of this is given in Figure 3 below. This sequence illustrates in simple terms, the transverse ray aberration diagram for a case of primary spherical aberration.
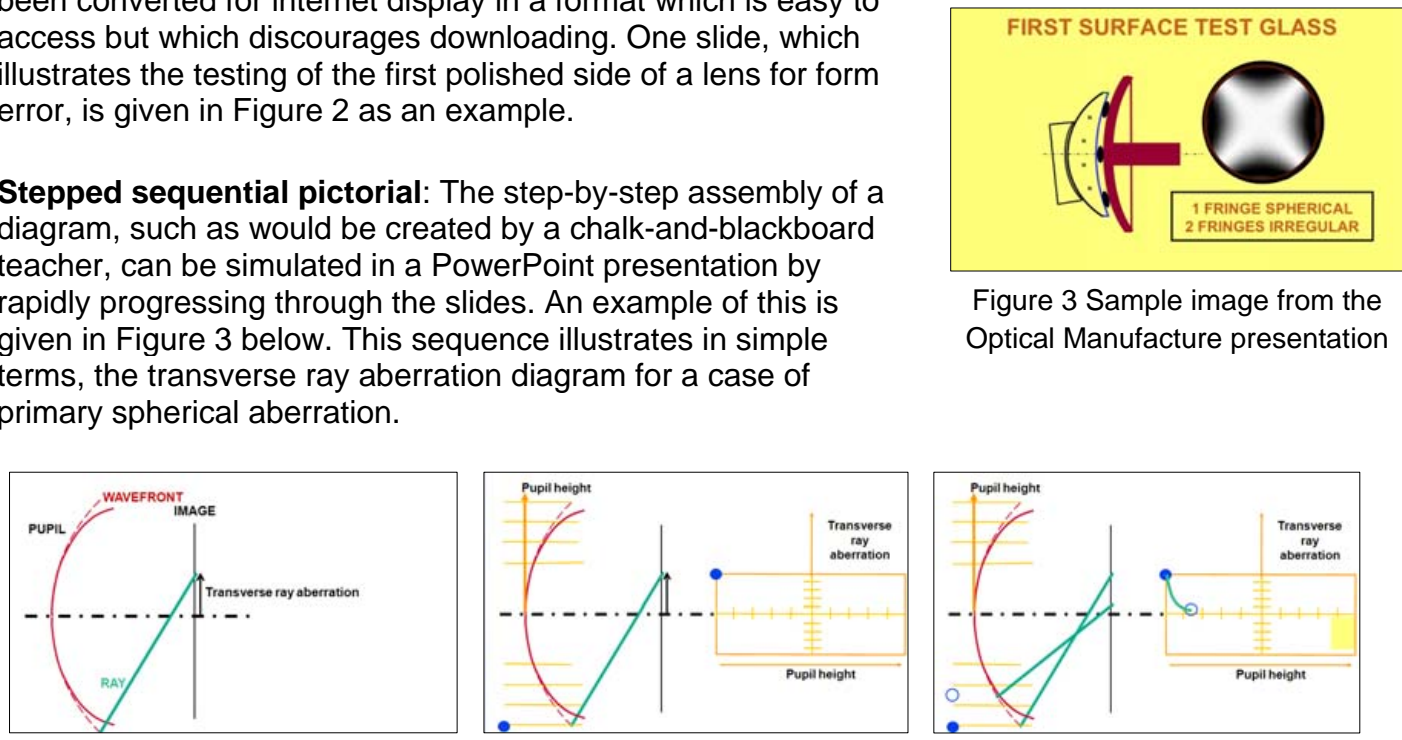

Figure 3 Sample image from the Optical Manufacture presentation
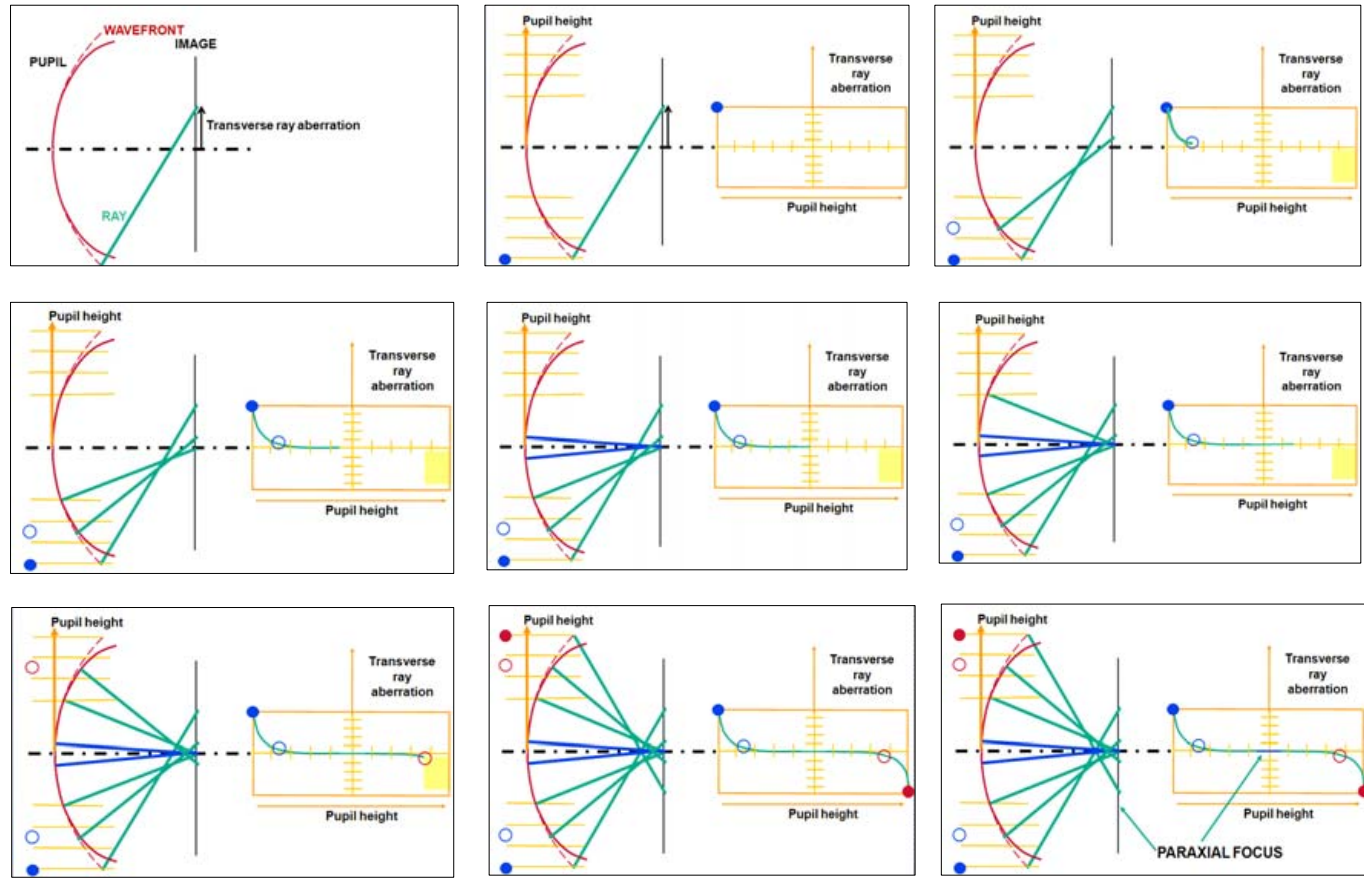

Figure 2 Sequence of slides for rapid presentation to illustrate the transverse ray aberration plotted as a function of pupil height

Interactive sequential pictorial: Once the presentation is on the internet in HTML, new possibilities open up. For example, one can allow the user to explore the pictorial area with the mouse to locate helpful short notes on a particular feature of the slide. This gives a sense of participation which is missing in a passive presentation. One example of this may be found in the "pop-up" associated with the slide ${ }^{7}$ illustrated in Figure 4, which is taken from the multilingual internet presentation Fundamental Optical Design. This password-protected course is offered as a precursor to all optical design training courses offered by the principal author. The diagram is an extension of the slides shown in Figure 3. Note the language and navigation buttons on the bottom toolbar. The presence of a "pop-up" is indicated by a slide number in violet. Another use of a "pop-up" is in the definition

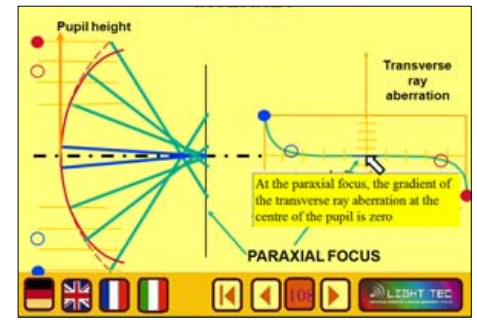

Figure 4 "Pop-up" used to comment on a pre-defined region of slide 108 
A similar interactivity is offered in the provision of a "commentary" on the same slide. This is intended as the text of an audio track to be recorded in the future for linking to this slide. The cursor must be placed on the Light Tec logo, as shown in Figure 5, to activate this feature. (Light Tec in France were the sponsors of the courses for which this material was originally developed). The commentary box has some transparency, and it moves with the cursor to enable the user to look at the parts of the diagram which it overlays.

Further interactivity is provided by "movie" presentations in the same course, which play, speeded up, a pre-denominated sequence of slides. For example, one illustrates the non-linear motions of a zoom objective ${ }^{7}$. The user should view in fullscreen mode, and press the cine button in the toolbar along the bottom to start the zoom motion demonstration. The opening slide in this sequence can be seen in Figure 6.

Of course the ability to switch languages has made this popular in European countries. Three examples are shown below in Figure 7 . Further language versions are planned in the future.

At present a password is issued for each course. However the site has been implemented in such a way as to allow each participant to have an individual password, if desired. The tutor could then ask for a report of how often each participant had logged onto the website, and for how long. This would be a useful step before implementing the next stage.

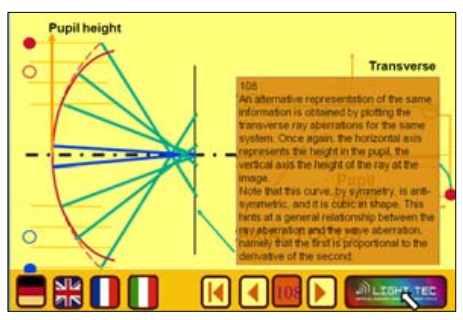

Figure 5 Commentary (currently only available in English) for slide 108 of Fundamental Optical Design

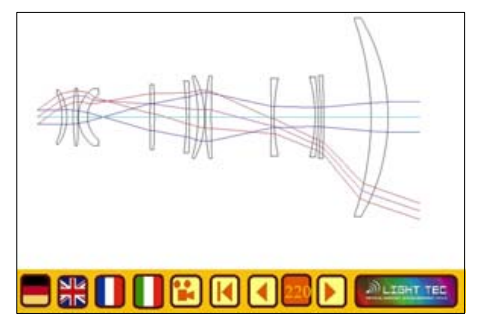

Figure 6 A zoom infra-red telescope illustrating non-linear motions of the zoom groups. This is activated using the "video" button shown between the language and navigation buttons
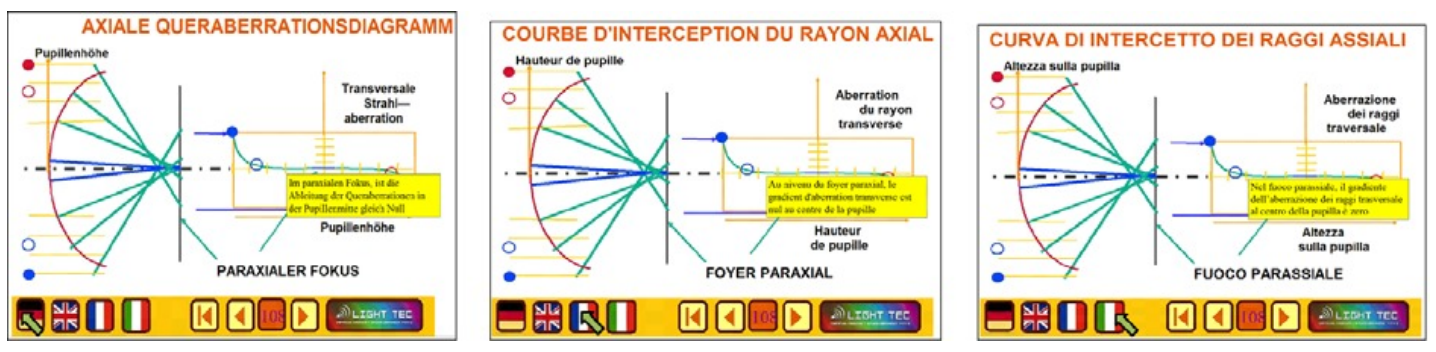

Figure 7 German, French and Italian versions of slide 108 in the Fundamental Optical Design presentation, showing translations of "pop-ups."

Conditional non-sequential presentation: It is not hard to envisage a scheme in which navigation through the presentation is conditional upon responses to multiple choice questions. This would give the fastest learners a quicker route through the course material, and allow for the provision of extra material for slow learners. The bar at the bottom of the slide presentations has been designed with enough flexibility to permit this to be added. Of course, the technology also exists to collect these responses and to report to the tutor. The tutor would then be in a position to give the student timely assistance via email or video link. Implementation of this, however, must wait till another day.

\section{CAN REAL DESIGN TASKS BE INCLUDED AS PART OF THE COURSE?}

The short answer to this question is an emphatic "yes." Teaching material written for the express purpose of helping a complete novice to undertake a number of optical design tasks has been written, and it is now available ${ }^{8}$. Expressed in the clearest possible terms, the participant is shown how to download and install the software (OSLO-EDU ${ }^{\circledR}$ ) and then undertake the aberrational analysis of a spherical concave mirror, and choose the best image plane. 
In the second presentation, a plane parallel plate of silica is introduced at the centre of curvature, and slider wheel optimisation (unique to OSLO) is used to determine the best aspheric coefficients to complete the design of an $\mathrm{f} / 1.4$ Schmidt camera objective.

The last stage is to design a $10 \mathrm{~mm} f / 2.840^{\circ}$ triplet objective using damped least squares optimisation. This uses OPIC, a routine which defines a merit function as described in the 2005 paper $^{9}$. OPIC is written in the OSLO macro language CCL, and is provided in ASCII format for download and compilation. More advanced students might also like to look for the global optimum of the "Monochromatic Quartet." Instructions for doing this are given in the 2005 paper.

\section{CONCLUSION}

Next time you need a telescope designed, Tailor-made or optics-off-the-shelf, Don't fumble in the Yellow Pages. Find A way in which to do the job yourself. Don't start to try to learn by heart the name Of every aberration - you will fail.

The principles in each case are the same: Reduce the spot size, maximise the Strehl. No earthly pleasure can provide such bliss, Nor mortal cup of happiness can fill, Than standing up in triumph, crying this: "My error function's going down the hill!"

Be confident, persist, don't flinch the fight. With distance learning you shall see the light!

\section{ACKNOWLEDGEMENTS}

The authors are grateful for helpful contributions from Esther Bartmann, Leo Chen, Alison Fairhurst, John Macdonald, Jon Maxwell and Naomi Lewis. OSLO is a registered trade mark of Lambda Research Corporation, Littleton, Mass., USA, who have been greatly supportive. The Fundamental Optical Design course is designed and hosted by Jean Marc Dennery (http://www.serade.org/). This and much of the other course material described here was developed under the auspices of Yan Cornil of Light Tec (www.lighttec.fr) and of Burkhard Fleck and Jürgen Bischoff of the University of Applied Sciences, Jena (www.jenall.de).

\section{REFERENCES}

[1] Blandford, B. "Remote teaching of optical design" Institute of Physics Photon02 (Cardiff 2002).

[2] Blandford, B, Chen, L, Fairhurst, A, Malaka, H. "Training modules for an advanced interactive course on optical design" Institute of Physics Photon06 (Manchester 2006).

[3] Farnsworth, A. "OpenCourseWare: College education without the student loans" The Christian Science Monitor May $13^{\text {th }} 2009$ http://features.csmonitor.com/innovation/2009/05/13/opencoursewarecollege-education-without-the-student-loans/

[4] Ezekiel, S, "Video Demonstrations in Lasers and Optics." (Massachusetts Institute of Technology: MIT OpenCourseWare). http://ocw.mit.edu (Accessed 2009). License: Creative Commons AttributionNonCommercial-Share Alike.

[5] Blandford, B. PDF document "Glossary of Optical Design" Unrestricted access for downloading from URL: http://www.amoptics.com/resources

[6] Blandford, B. "Lens Manufacture" "Optical Assembly" Unrestricted access for viewing at URL http://www.amoptics.com/resources 
[7] Blandford, B. The slide from the Aberrations section of Fundamental Optical Design is accessible without a password at URL http://fod.serade.org/fod9_slide108.html. The video demonstration of a zoom infrared telescope is also accessible at URL http://fod.serade.org/fod9_slide220.html

[8] Blandford, B. PDF documents: "Downloading OSLO-EDU" "Your first OSLO session" "Designing a Schmidt camera objective" "Optimising using OPIC" and "OPIC CCL for OSLO-EDU" Unrestricted access for downloading from URL: http://www.amoptics.com/resources

[9] Blandford, B. "OPIC: a kit for rapid merit function construction for use with all versions of OSLO including OSLO-EDU" SPIE Optical Design and Engineering II, volume 5962:15 (Jena 2005). 